\title{
Sürdürülebilirlik Açısından Mermer Atıklarının Karayolu İnşaatında Değerlendirilmesi: Ekonomik Analiz Örneği
}

\author{
Altan YILMAZ*1 (D) \\ ${ }^{1}$ Burdur Mehmet Akif Ersoy Üniversitesi, Mühendislik Mimarlık Fakültesi, İnşaat Mühendisliği Bölümü, 15100, \\ Burdur, Turkey
}

(Alınış / Received: 29.01.2020, Kabul / Accepted: 30.05.2020, Online Yayınlanma / Published Online: 20.08.2020)

\author{
Anahtar Kelimeler \\ Yol üstyapısı, \\ Mermer atıkları, \\ Ekonomik analiz, \\ Birim maliyet
}

Özet: Günümüzde mineral agrega kullanım alanları büyük bir hızla artmakta olmasına rağmen doğal agrega kaynakları giderek azalmaktadır. Buna karşılık ülkemizdeki mermer fabrikalarının atıklarının büyük bir kısmı değerlendirilememekte, işletme sahalarında veya yakınlarındaki depo alanlarında depolanmaktadır. Mermer ișleme tesislerinde ham blokların ișlenmesi ile ortaya çıkan artık miktarı genellikle \%30 - \%45 civarında olmaktadır. Mermer atıklarının yığınlar halinde biriktirilmesi hem çevreye olumsuz etkileri olmakta hem de ekonomik olarak kayıplara sebep olmaktadır. Bu çalışmada atık mermer agregasının yol üstyapısında temel tabakalarında doğal agrega yerine alternatif kullanımı düşünülerek, doğal malzeme ile mukayeseli olarak ekonomik analizi yapılmıștır. Çalışmada öncelikle atık malzemelerin ve doğal agreganın birim maliyetleri belirlenmiştir. Maliyet analizinde sökme - kırma - eleme - sınıflandırma - yükleme ve nakliye maliyetleri arasında olası senaryolar dikkate alınmıștır. Yapılan maliyet hesabı neticesinde mermer atıklarının ham madde maliyeti olmaması sebebiyle, birim maliyeti doğal agreganın \%50'si kadar çıkmıştır. Elde edilen birim maliyet farklarından hareketle, sonuç olarak mermer agregasının ekonomik olarak taşınabileceği belirli bir mesafe $\left(\mathrm{M}_{\mathrm{e}}\right)$ belirlenmiştir. Başa baş mesafesi olarak bulunan bu uzaklığın göz ardı edilemeyecek ölçüde olduğu tespit edilmiştir.

\section{Utilization of Marble Waste into the Highway Pavement Layers in the Mean of Sustainability; An Example of Cost Analysis}

\section{Keywords}

Highway pavements,

Marble waste,

Cost analysis,

Unit cost

\begin{abstract}
Today, although mineral aggregate usage areas are increasing rapidly, natural aggregate resources are decreasing gradually. On the other hand most of the marble waste produced by the factories in Turkey is not in use. Inert wastes are stored at factory sites or in storage areas nearby the production area. The amount of marble waste produced by the processing of raw blocks in marble factory is generally around $30 \%-45 \%$. An uncovered marble waste in stock pile both has negative effects on the environment and causes economic losses. In this study, considering the alternative usage of waste marble aggregate instead of natural mineral aggregate in the road pavements, an economic analysis has been investigated in comparison with natural aggregate. In the study, firstly, unit costs of waste materials and natural aggregates were determined. In the cost analysis, possible scenarios between ripping - crushing - screening - classification - loading and transportation costs are taken into consideration. In the cost analysis, since the marble waste has not raw material charge, the unit cost has been calculated as the half of the natural aggregate. As a result, based on the unit cost differences, a certain distance $\left(\mathrm{M}_{\mathrm{e}}\right)$ at which the marble aggregate can be carried economically has been determined. This $\left(\mathrm{M}_{\mathrm{e}}\right)$ distance, which is found as the break-even distance, cannot be ignored.
\end{abstract}




\section{Giriş}

Yüksek miktarda sıcaklık ve basınçla başkalaşım geçirmiş olan kalkerlere mermer adı verilmektedir. Endüstriyel anlamda ise kolaylıkla cilâlanabilen ve kolaylıkla parlatılabilen taşlar, mermer olarak tanımlanmaktadır $[1,2]$. Mermerin en önemli fiziksel özelliği sahip olduğu renk olmakla birlikte beyaz haricindeki renkler mermerin içeriğinde yer alan yabancı maddelerden dolayı oluşmaktadır. Mermerin kalitesi sahip olduğu renk, saydamlık, dayanıklılık, üzerindeki çatlak ve boşluk miktarı gibi etkenlere göre belirlenir [3].

İstenilen boyut ve özelliklerde üretilebilen doğal taşların daha kolay ve daha ucuz temin edilmesi son yıllarda mermer sektörüne olan ilgiyi arttırmıştır. Dünyadaki mermer ve doğal taş rezervleri araştırıldığında Türkiye, dünya'daki rezervler arasında sayılı ülkeler arasında yer almaktadır. Geliştirilecek teknoloji yatırımlarıyla ve nitelikli işgücünün temin edilmesi ile doğal taş sektörünün daha da yükseleceği düşünülmektedir [4].

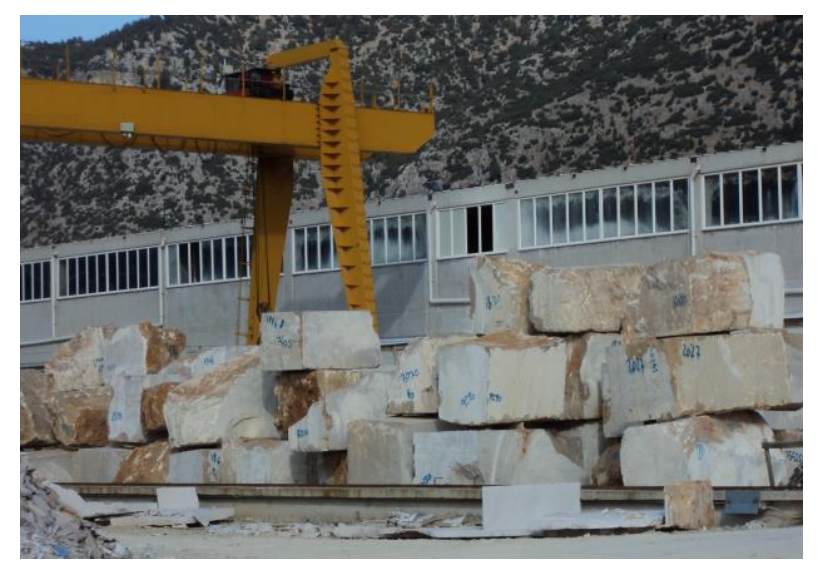

Şekil 1. Fabrikada işlenmeyi bekleyen mermer blokları.

\subsection{Mermer Atıkları ve Kullanım potansiyeli}

Mermer fabrikalarında üretim esnasında atıklar oluşmaktadır. $\mathrm{Bu}$ atıklar, fabrikaların içerisinden toplanıp fabrikanın dışında üretime engel teşkil etmeyen alanlarına gelişigüzel olarak yığılmaktadır. Ocaktan çıkarılarak işlenmek üzere fabrikaya getirilmiş mermer blokları Şekil.1'de, proses sonrası açığa çıkan parça mermer atıkları da Şekil.2 ve Şekil.3'de görülmektedir. Mermer üretiminin yoğun olduğu bölgelerde mermer atıklarının yığınlar halinde biriktirilmesi hem çevreye olumsuz etkileri olmakta hem de ekonomik olarak kayıplara sebep olmaktadır [5].

Atık mermer miktarı, mermerin mineralojisine, mermer kayacının süreksizlik ve çatlak yapısına, ocaktan mermer çlkartma işlemine ve mermer fabrikalarındaki işletime bağlı olarak farklılıklar göstermektedir [6]. Doğal taş işleme tesislerinde ham blokların işlenmesi ile ortaya çıkan artık miktarı genellikle $\% 30$ - \%45 olarak ifade edilmektedir [7].
Bazı araştırmacılar bu miktarın \%40-60 aralı̆̆ında olduğunu belirtmişlerdir [8].

Mermer ocaklarında oluşan atıklar, Dünya genelinde etkisiz atık (inert) olarak değerlendirilmektedir. Ancak, bu atıklar, etkisiz atık olma özelliğine rağmen mermer sektörünün en önemli sorunlarından birisidir [9].

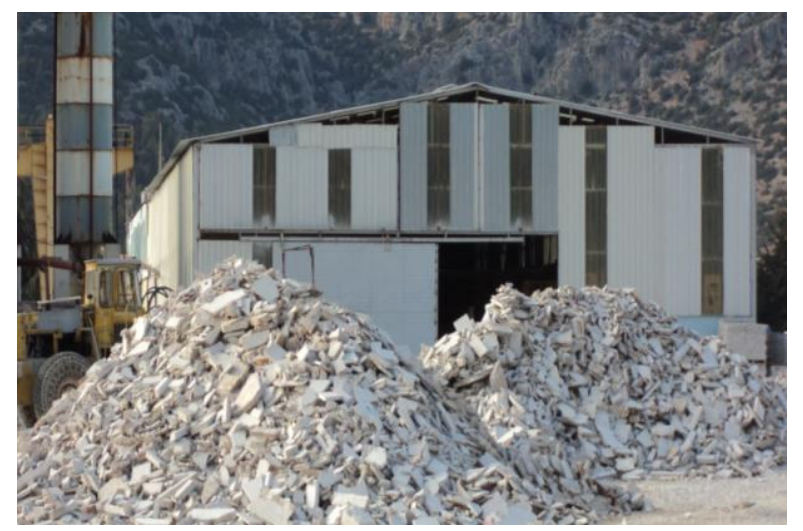

Şekil 2. Fabrika sahasında birikmiş mermer atıkları.

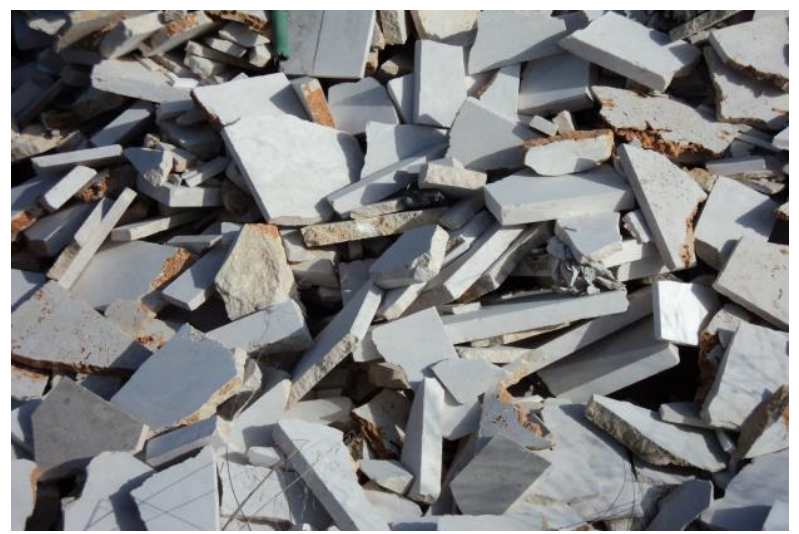

Şekil 3. Parça mermer atıklarının yakından görünümü.

Mermerin fabrikalarından çıkan mermer atıkları, belirli boyutlarda kırıldıktan sonra farklı kullanım alanları bulabilmektedir. Beton ve asfalt karışımlarda agrega olarak, karayolu dolgularında ve baraj inşaatlarında dolgu malzemesi olarak, taşkın koruma amaçlı yapılan çalışmalarda, suni mermer üretiminde, karo mozaik ve mermer süsleme malzemesi olarak kullanılmaktadır $[10,11]$. Ancak parça mermer atıklarının sürekli ve düzenli değerlendirme imkânlarının mevcut olmadığı çoğunlukla fabrika stok sahalarında biriktirildiği gözlenmiştir. $\mathrm{Bu}$ çalışamaya konu olan mermer atıkları da değerlendirilme potansiyeli olmayan fabrika atık sahasından uzaklaştırılması istenen atıklardan olușmaktadır.

Son yıllarda tamamı geri dönüştürülemeyen atık malzemelerin farklı alanlarda kullanılabilir hale getirilmesi önemli bir çalışma konusu olmuștur [12]. Mermer atıklarının geri dönüştürülerek karayolu inşaatında kullanımı ile ilgili farklı çalışmalar yapılmıştır. Bunlardan bazıları; Akbulut ve Gürer, yapmış oldukları çalışmada, Afyon bölgesinde üretim 
sırasında ortaya çıkan atık mermer parçalarından oluşan agregaların yol üstyapısında bitümlü karışımlarda kullanılabilirliğini incelemişlerdir [13, 14]. Orta dereceli taşıt trafiği olan yollarda bu malzemelerin uygulanabilir olduğu sonucunu elde etmişlerdir. Ural ve Yakşe, Bilecik ilinde ortaya çlkan mermer atıklarının yol temel malzemesi olarak değerlendirilmesi yönünde araştırma yapmışlardır [15]. Sonuçta, Bilecik ilinin 3 farklı bölgesinden alınan mermer atıklarının Karayolları Teknik Şartnamesinde belirtilen alttemel/temel malzemesi özelliklerini sağladığı görülmüştür. Özdemir vd., Malatya Bej, Adıyaman Emrador ve Erzurum traverten atıklarından elde edilen agregaların yol inşaatlarının temel ve alt temel tabakalarında kullanımını incelemişlerdir [16]. Araştırma sonucunda Karayolu teknik şartnamesi dikkate alınarak Malatya Bej, Adıyaman Emrador ve Erzurum traverten atıklarının temel ve alttemel tabakalarında kullanılabilir olduğu görülmüştür. Terzi ve Karaşahin, mermer tozu atıklarının bitümlü sıcak karışımlarda mineral filler olarak kullanımı araştırmışlardır [17]. Sonuç olarak mermer tozunun yaygın olarak bulunduğu bölgelerde filler olarak kullanılabilir olduğu tespit edilmiştir. Okagbue ve Onyeaobi, mermer tozunu yol tabanlarında görülen kırmızı tropikal zeminlerin (laterit) stabilizasyonunda kullanımını araştırmışlardır [18]. Atterberg limitleri, Kaliforniya taşıma oranı (CBR), serbest basınç dayanımı ve Proctor testleri uygulanmıştır. Sonuç olarak mermer tozunun zeminin geoteknik özelliklerini iyileştirdiği gözlemlenmiştir. Yıldız, yaptığı çalışmada mermer tozu ve parça mermer atıklarının yol inşaatında kullanımını araştırmıştır [6]. Parça atıkların yol temel tabakasında, toz atıkların ise taban zemini içerisine karıştırılarak stabilizasyonda kullanımı test edilmiştir. Parça atıklar için elde edilen analiz sonuçlarında, temel tabakası için Yollar fenni şartnamesinde belirtilen şartların sağlandığı tespit edilmiştir.

Literatür taramalarında görüldüğü üzere, çalışmalarda genellikle geri dönüşüm (mermer) agregalarının fiziksel ve mekanik özellikleri incelenmiş ve bu özelliklerin pozitif yönde olduğu tespit edilmiştir. Yukarıda değinilen çalışmalardan elde edilen bulgular (Mermer atıklarının mühendislik özellikleri) Tablo Ek. A'da toplu olarak verilmiştir. Tablodaki bulgular incelendiğinde mermer atıklarından elde edilen granüler malzemelerin tümünün karayolu temel ve alttemel tabakalarında istenen malzeme kriterlerini (Karayolları Teknik Şartnamesini) karşıladığı ve doğal kırma-taşlar yerine kullanım imkânı olduğu görülmektedir.

$\mathrm{Bu}$ çalışmada ise literatürde bir eksiklik olarak tespit edilen mermer atıklarının doğal agrega ile mukayeseli olarak ekonomik analizi konusu ele alınmıştır. Atık mermer agregasının yol üstyapısında temel tabakalarında doğal agrega yerine alternatif kullanımı senaryosu dikkate alınarak ekonomik analiz gerçekleştirilmiştir.

\section{Materyal ve Metot}

Son yıllarda Batı Akdeniz bölgesinde mermercilik faaliyetleri öne çıkmaktadır. Batı Akdeniz bölgesinde mevcut mermer fabrikalarının yoğun olarak bulunduğu alanlardan birisi de Burdur ilinin Bucak ilçesidir. Bucak ilçesinde, gerek iç piyasa ihtiyacı gerekse ihracat amaçlı olarak mermer ürünleri üretilmektedir. Özellikle 1980 yılından sonra bulunan mermer rezervlerinin üretime açılması sonucu Bucak ilçesinde mermer taşlarını işleyen fabrika sayısında belirgin bir artış görülmüştür. Bucak Ticaret ve Sanayi Odası Kayıtlarında Bucak ilçesinde işletilmekte olan mermer ocağı sayısının 18, faaliyette olan mermer fabrikası sayısının 50 ve mermer makineleri üretimi yapan firma sayısının ise 13 olduğu belirtilmektedir [19].

Mermercilik sektöründe, doğal tașın ürün haline getirilmesi ve satışı ekonomiye katkı sağlarken, sektörün devamlılığı ve sürdürülebilir geri-dönüşüm açısından mermer atıklarının oluşturduğu çevre sorunlarına da çözüm bulunması gerekmektedir. Bu çalışmada Burdur ili Bucak ilçesinde ortaya çıkan mermer atıkları esas alınarak, mermer agregasının doğal agrega yerine alternatif kullanımı düşünülerek, ekonomik analiz yapılmıştır.

\subsection{Mermer atıklarının ekonomik analizi}

Çalışmada öncelikle atık malzemelerin ve doğal malzemenin birim maliyetlerinin belirlenmesi gerekmektedir. Maliyet analizinde taşıma uzaklıkları, nakliye maliyetleri, sökme - kırma - eleme sinıflandırma, yükleme maliyetleri arasında olası senaryolar dikkate alınmıştır.

Malzeme maliyeti, üstyapıda kullanılacak olan malzemenin kendi maliyeti (ham madde olarak maliyeti) dikkate alınmalıdır. $\mathrm{Bu}$ anlamda, doğal agrega için ocak taşının rayiç fiyatı malzeme maliyeti olmaktadır. Mermer atıkları için böyle bir maliyet söz konusu değildir. $\mathrm{Bu}$ malzemenin zaten fabrika sahasından uzaklaştırılması ve bertaraf edilmesi arzu edilmektedir.

Sökme maliyeti, doğal agrega için taş ocağından patlayıcı madde kullanarak veya kullanmadan ocak taşı çıkartılması ve konkasöre girecek boyutta ufaltılması işlemidir. Mermer atıkları, fabrika sahasında birikmiş bir malzeme olduğu için som kayadan ocak taşı çıkarmak kadar zahmetli bir işlem olmayacaktır. Mermer atıkları irili ve ufaklı olarak karışık şekilde alana atıldıkları için çok rahat ekskavatörler veya loder ile alınabilecektir.

Kırma işleminin hem doğal malzeme için hem de mermer atıkları için yapılması gerekmektedir. Çünkü temel tabakasında kullanılacak olan malzemenin şartnameler gereği en az \%50'sinin kırılmış malzeme olması gerekmektedir. $\mathrm{Bu}$ açıdan iki malzeme türü 
arasında kırma maliyeti farklı olmayacaktır. Şantiye sahası içindeki bir kırıcı tesisi bu işlemi rahatlıkla yapabilecektir.

Kırıcıdan geçerek değişik boyutlarda agrega niteliğine dönüşen atık malzemenin elenerek sınıflandırılması işlemi yine yerinde şantiye içinde yapılabilecektir. $\mathrm{Bu}$ işlem de doğal agrega kırmaeleme tesislerinin maliyeti ile aynı olacaktır. Yükleme işleri için malzemeler arası bir fark bulunmamaktadır. Gerek sınıflandırılmış atık malzeme ve gerekse kırmataş için yükleme maliyetleri eşdeğer düzeyde olacaktır.

Nakliye maliyeti toplam maliyeti oluşturan unsurların başında gelmektedir. Nakliyenin maliyeti, taşıyıcı aracın malzemeyi götüreceği uzaklıktan doğrudan etkilenmektedir. Bunun yanı sıra doğal malzeme ocakları değişik bölgelere dağılmış vaziyette olmasına rağmen mermer atığının bulunduğu bölge sabittir. Dolayısıyla mermer agregasının ekonomik olarak taşınabileceği belirli bir mesafe olacaktır [21].

Ekonomik analizde kullanılan birim maliyetler hesaplanırken, Çevre ve Şehircilik Bakanlığı 2018 yılı Birim Fiyat Analizlerinden ve Karayolları Genel Müdürlüğü 2018 yılı Birim Fiyat Analizlerinden yararlanılmıştır $[22,23]$. Ekonomik analizde kullanılan birim maliyetler için özet bilgi Tablo 1'de verilmiştir.

\section{Bulgular}

\subsection{Doğal agrega birim maliyet analizi}

Doğal agrega maliyeti olarak, patlayıcı madde kullanılarak ocaktan çıkartılan moloz taşın maliyeti, ocaktan çıkan taşın elle veya kompresörle hazırlanması, araca yüklenmesi, konkasörde kırılarak ve elenerek sınıflara ayrılması, taşıma aracına yüklenerek şantiyeye nakliyesi dikkate alınmıştır.

Tablo.2'den görüldügü gibi doğal agregadan imal edilen bir $\mathrm{m}^{3}$ malzemenin birim maliyeti 30,85 TL olarak bulunmuştur. Doğal agreganın yığın (bulk) birim ağırlığı 1,6 ton $/ \mathrm{m}^{3}$ olarak alınırsa, bir ton malzemenin birim maliyeti 30,85/1,6 = 19,28 TL olur.

\subsection{Mermer agregası birim maliyet analizi}

Mermer agregası maliyeti olarak, atık sahasından yükleyici ile mermer atıklarının yüklenmesi, konkasörde kırılarak ve elenerek sınıflara ayrılması, taşıma aracına yüklenerek şantiyeye nakliyesi hesap edilmiştir. Birim maliyet hesabında Karayolları Genel Müdürlüğü'nün kullanmakta olduğu 15.113/K Poz numaralı "Taş ocağından konkasörle kırılmış ve elenmiş 25mm'lik temel malzemesi temini" analiz kalemleri esas alınarak, atık mermer agregası için gerekli dönüşümler yapılmıştır (Tablo.3).

Tablo.3'den görüldüğü gibi atık mermerden imal edilen bir $\mathrm{m}^{3}$ temel malzemesinin nakliye hariç birim maliyeti 15,42 TL olarak hesaplanmıștır. Mermerin birim ağırlığı ortalama 1,9 ton $/ \mathrm{m}^{3}$ olarak alınırsa, bir ton temel malzemesinin birim maliyeti $15,42 / 1,9=$ 8,12 TL olur.

Yapılan maliyet hesabı neticesinde görülmüştür ki, mermer atıklarının ham madde maliyeti olmaması sebebiyle, birim maliyeti doğal agreganın (\%50'si) yarısı kadardır.

\subsection{Taşıma maliyeti}

Taşıma maliyetleri açısından, her iki malzeme için de aynı eşitlik kullanılacağı için burada en önemli etken taşıma mesafesidir. Taşıma maliyeti, 10 km'ye kadar mesafeler için kullanılan eşitlikteki köklü ifade nedeniyle uzaklığın üslü formu ile tanımlanmaktadır (Denk.1). 10 km'den daha uzak taşımalar için maliyet, uzaklık ile doğrusal ilişki içindedir (Denk.2) [24].

Karayolları Genel Müdürlüğü Taşıma Genel Şartnamesine göre, karayolu taşımalarında aracın cinsine bakılmaksızın, taşıma bedeli motorlu taşıt formüllerine göre ödenir [25]. Taşıma mesafesi, taşıma yolu üzerinden ölçülen, eğimi en çok \%10 (ortalama) olan her cins kaplamalı yolda, karayolu taşıma formüllerine göre aşağıdaki şekilde hesap edilir.

Tablo 1. Ekonomik analizde kullanılan birim maliyetler (2018)

\begin{tabular}{|c|c|c|c|c|}
\hline & Açılkama & Poz No & Birimi & Fiyatı (TL) \\
\hline A & $\begin{array}{l}\text { Ocak taşından konkasörle kırılmış ve elenmiş } 25 \mathrm{~mm} \\
\text { temel malzemesi temini }\end{array}$ & $15.113 / \mathrm{K}(\mathrm{KGM})$ & $\mathrm{M}^{3}$ & $-*$ \\
\hline B & El ile veya kompresörle ocaktan taş hazırlanması & 08.021/K (KGM) & $\mathrm{M}^{3}$ & 12,35 \\
\hline $\mathrm{C}$ & Lastik tekerlekli yükleyicinin 1 saatlik ücreti & 03.521 (ÇŞB) & Saat & 97,99 \\
\hline D & Konkasörün 1 saatlik ücreti & $03.530(\mathrm{KGM})$ & Saat & 226,19 \\
\hline E & Her cins ve tonajda motorlu araç taşıma katsayısı(k) & 02.017 (ÇŞB) & $(\mathrm{k}) \mathrm{TL}$ & 278 \\
\hline $\mathrm{F}$ & İşçilik (Formen, Düz işçi) & 01.409-01.501 (ÇŞB) & Saat & $18,25-9,10$ \\
\hline
\end{tabular}


Tablo 2. Doğal agrega birim maliyet analizi

\begin{tabular}{|c|c|c|c|c|c|}
\hline \multicolumn{6}{|c|}{ Poz Numarası : Doğal Agrega Analiz (Özel) } \\
\hline \multicolumn{6}{|c|}{ Açıklama : Taş ocağından konkasörle kırılmış ve elenmiş 25mm (1inç) lik temel malzemesi temini maliyeti } \\
\hline \multicolumn{6}{|l|}{ Birim : $\mathrm{M}^{3}$} \\
\hline \multirow[t]{2}{*}{ Kod No } & Açılklama & Birim & Birim Miktar & Fiyatı & Toplam (TL) \\
\hline & $\% 50,03$ MALZEME & & & & 12,35 \\
\hline \multirow[t]{2}{*}{$08.021 / \mathrm{K}$} & Ocaktan taş hazırlanması & $\mathrm{M}^{3}$ & 1 & 12,35 & 12,35 \\
\hline & \%12,91 İȘÇİLIK & & & & 3,19 \\
\hline 01.409 & Formen & Sa & 0,025 & 18,25 & 0,46 \\
\hline \multirow[t]{2}{*}{01.501} & Düz ișçi & Sa & 0,3 & 9,1 & 2,73 \\
\hline & \%32,83 MAKINA & & & & 8,10 \\
\hline 03.521 & $\begin{array}{l}\text { Lastik tekerlekli yükleyicinin bir saatlik } \\
\text { ücreti }\end{array}$ & Sa & 0,025 & 97,99 & 2,45 \\
\hline \multirow[t]{2}{*}{03.530} & $\begin{array}{l}\text { Konkasörün } 1 \text { saatlik ücreti (Primer } \\
15 \times 24 \text { inç+sekonder } 24 \times 16 \text { inç eleme ve } \\
\text { yükleme tertibatı) }\end{array}$ & Sa & 0,025 & 226,19 & 5,65 \\
\hline & \%4,22 DİĞER & & & & 1,04 \\
\hline \multirow[t]{4}{*}{02.017} & "k" katsayısı (taşıt) & $\mathrm{K}$ & 0,00375 & 278 & 1,04 \\
\hline & & & & Toplam & 24,68 \\
\hline & & & Yükleı & Karı \%25 & 6,17 \\
\hline & & & & el Toplam & 30,85 \\
\hline
\end{tabular}

Tablo 3. Mermer agregası birim maliyet analizi

Poz Numarası: Mermer Agregası Analiz (Özel)

Açıklama : Atık sahasından konkasörle kırılmış ve elenmiş 25mm (1inç) lik temel malzemesi temini maliyeti

\begin{tabular}{|c|c|c|c|c|c|}
\hline \multicolumn{6}{|l|}{ Birim : $\mathrm{M}^{3}$} \\
\hline Kod No & Açıklama & Birim & Birim Miktar & Fiyatı & Toplam (TL) \\
\hline & $\% 0,0$ MALZEME & & & & - \\
\hline & - & $\mathrm{M}^{3}$ & & & - \\
\hline & \%25,83 İşÇİLíK & & & & 3,19 \\
\hline 01.409 & Formen & Sa & 0,025 & 18,25 & 0,46 \\
\hline \multirow[t]{2}{*}{01.501} & Düz işçi & Sa & 0,3 & 9,1 & 2,73 \\
\hline & $\% 65,71$ MAKINA & & & & 8,10 \\
\hline 03.521 & $\begin{array}{l}\text { Lastik tekerlekli yükleyicinin bir saatlik } \\
\text { ücreti }\end{array}$ & Sa & 0,025 & 97,99 & 2,45 \\
\hline \multirow[t]{2}{*}{03.530} & $\begin{array}{l}\text { Konkasörün } 1 \text { saatlik ücreti (Primer } \\
15 \times 24 \text { inç+sekonder } 24 \times 16 \text { inç eleme ve } \\
\text { yükleme tertibatı) }\end{array}$ & Sa & 0,025 & 226,2 & 5,65 \\
\hline & \%8,45 DİĞER & & & & 1,04 \\
\hline \multirow[t]{4}{*}{02.017} & "k" katsayısı (taşıt) & $\mathrm{K}$ & 0,00375 & 278 & 1,04 \\
\hline & & & & Toplam & 12,33 \\
\hline & & & Yükle & Karı \%25 & 3,08 \\
\hline & & & & I Toplam & 15,42 \\
\hline
\end{tabular}


1) $\mathrm{M}<10 \mathrm{~km} . y e$ kadar (10 km dahil) olan taşımalar, Poz No. 07.005/K'dan;

$$
\begin{gathered}
F=A \cdot K \cdot 1,25 \cdot 0,00017 \cdot \sqrt{M}(\mathrm{TL} / \mathrm{Ton}) \\
\mathrm{M}=\text { Metre olarak alınır. }
\end{gathered}
$$

2) $\mathrm{M}>10$ km olan taşımalar, Poz No. 07.006/K'dan;

$$
\begin{gathered}
F=A \cdot K \cdot 1,25 \cdot(0,0007 \cdot M+0,01)(\mathrm{TL} / \mathrm{Ton}) \\
\mathrm{M}=\text { Km olarak alınır. }
\end{gathered}
$$

Motorlu taşıt formüllerindeki " $K$ " değeri, rayiç listesindeki Poz 02.017'den her cins ve tonajda motorlu araç için taşıma katsayısıdır. 2018 yılı için "K" değeri 278 dir. "A" katsayısı yolun fiziki durumu ve kaplaması ile ilgili katsayıdır ve genellikle 1-2 arasında değerler alır. Yol düz ve kaplamalı ise genellikle "1" alınır [25].

"M" km'lik taşıma mesafesi için nakliye maliyeti:

1) $\mathrm{M}<10 \mathrm{~km}$. olan taşımalar için Denklem 1'den $A=1$ ve $K=278$ için;

$$
\begin{aligned}
& F=1 \cdot 1,25 \cdot 278 \cdot 0,00017 \cdot \sqrt{M}=0,059 \cdot \sqrt{M} \\
& \text { (TL/Ton) }
\end{aligned}
$$

2) $M>10 \mathrm{~km}$ olan taşımalar için Denklem 2 'den

$$
\begin{aligned}
& \mathrm{A}=1 \text { ve } \mathrm{K}=278 \text { için; } \\
& F=1 \cdot 1,25 \cdot 278 .(0,0007 \cdot M+0,01)= \\
& F=0,243 \cdot M+3,475 \quad \text { (TL/Ton) }
\end{aligned}
$$

Olarak bulunur.

\subsection{Ekonomik taşıma mesafesi hesabı}

Taşıma maliyetlerinde yükleme-boșaltma bedeli ayrıca ödenir. Yükleme-boșaltma bedeli olarak, Çevre ve Şehircilik Bakanlığı Birim Fiyat Analizlerinden Y.09.005/1 No'lu poz "Moloz, blokaj, kırma taş, balast, kaldırım taşının taşıtlara yükleme ve boşaltılması" kullanılmıştır.

Y.09.005/1 Yükleme-boşaltma maliyeti (2018 Yılı) : $2,68 \mathrm{TL} / \mathrm{m}^{3}$ dür.

Bu değer "Ton" cinsinden ifade edildiğinde 2,68/1,9= 1,41 TL/Ton olur.

Bu durumda yeni taşıma formülü ( $M>10 \mathrm{~km})$;

$$
F=0,243 \cdot M+3,475+1,41 \quad(\mathrm{TL} / \mathrm{Ton})
$$

şeklini alır.

Doğal agrega maliyeti bir ton temel malzemesi için 19,28 TL bulunmuştu. Mermer atıklarından oluşan bir ton malzemenin birim maliyeti de 8,12 TL bulunmuştu. Bir ton temel malzemesi için aradaki fiyat farkı 19,28 - 8,12 = 11,16 TL'dir. Aradaki fiyat farkının taşıma mesafesi olarak kaç kilometre'ye karşılık geldiğini hesaplamak için " $F$ " taşıma maliyetini 1 ton temel malzemesi için bulunan fiyat farkına (11,16 TL) eşitleyerek, "M" taşıma mesafesi bulunmuştur.

$$
\begin{aligned}
& F=0,243 \cdot M+3,475+1,41=11,16 \\
& \text { (TL/Ton) } \\
& \text { M }=25,82 \text { Km olarak bulunur. }
\end{aligned}
$$

Bu taşıma mesafesi mermer agregası ve doğal agrega için başa-baş mesafesi ( $\mathrm{M}_{\mathrm{e}}$ ) olarak tanımlanır. 25,82 Km'lik taşıma mesafesi için mermer agregasının nakliye dahil toplam birim maliyeti;

Toplam birim maliyet $=8,12+11,16=19,28 \mathrm{TL} / \mathrm{Ton}$ olur.

Bu uygulamada yapılan kabullerde değişiklik olması halinde, ekonomik taşıma mesafeleri değişebilecektir. Örneğin, fabrika mermer kullanımı için gereken altyapıyı kendisi kurmaz da başka bir firmaya verirse ayrıca ham madde maliyeti isteyebilecektir. $\mathrm{Bu}$ maliyet doğal agrega maliyeti kadar yüksek olmasa da ekonomik taşıma mesafelerinin kısalması anlamına gelir.

\section{Tartışma ve Sonuç}

$\mathrm{Bu}$ çalışmada mermer atıklarının kullanımının ekonomik analizi yapılmıştır. Bu amaçla, mermer agregasının yol üstyapısında temel tabakalarında doğal agrega yerine alternatif kullanımı düşünülerek, doğal malzeme ile mukayeseli olarak analiz yapılmıştır.

Çalışmada öncelikle atık malzemelerin ve doğal malzemenin birim maliyetleri belirlenmiştir. Mermer atıkları için malzeme maliyeti olmaması önemli bir ekonomik avantaj oluşturmuştur. Çünkü atık bir malzeme olduğu için zaten fabrika sahasından uzaklaştırılması ve bertaraf edilmesi arzu edilmektedir. Birim fiyat analizleri neticesinde; atık mermerden oluşan bir ton temel malzemesinin birim maliyeti 8,12 TL, doğal agreganın birim maliyeti ise 19,28 TL bulunmuştur. Mermer atıklarından elde edilen malzemenin birim maliyeti doğal agreganın yaklaşık yarısı kadardır.

Nakliye maliyeti ise taşıyıcı aracın malzemeyi götüreceği uzaklıktan doğrudan etkilenmektedir. Dolayısıyla mermer agregasının ekonomik olarak taşınabileceği belirli bir mesafe tespit edilmiştir. Malzemeler arasındaki fiyat farkının taşıma mesafesi olarak kaç kilometre'ye denk geldiğini hesaplamak için, " $F$ " taşıma maliyeti denklemi, bir ton temel malzemesi için bulunan fiyat farkına $(11,16 \mathrm{TL})$ eşitlenerek, "Me" ekonomik taşıma mesafesi 25,82 Km olarak bulunmuştur. Bu taşıma mesafesi mermer agregası ve doğal agrega için başa-baş mesafesi 
olarak tanımlanır. Diğer bir anlatımla fabrika atık sahasına 25,82 km uzaklıktaki bir karayolu şantiyesi için atık mermer agregası getirerek kullanmak, şantiyenin hemen yanı başındaki bir ocaktan doğal agrega kullanımı ile aynı maliyeti vermektedir. Her yol şantiyesinin yanı başında bir taş ocağı bulunması mümkün olmayacağından mermer atıkları için ekonomik taşıma mesafesi bu değerin daha da üzerinde olacaktır $\left(\mathrm{M}_{\mathrm{e}} \geq 25,82 \mathrm{~km}\right)$.

Sonuç olarak atık mermer agregalarının karayolu inşaatında kullanılmakta olan geleneksel doğal agregalara kıyasla, belirli taşıma mesafelerinde daha ekonomik bir ürün olduğu ayrıca atıkların azaltılması, tarım alanlarından uzaklaştırılması ve çevresel duyarlılık yönleriyle de iyi bir alternatif oluşturacağı değerlendirilmektedir.

Yapılan ekonomik değerlendirmede mermer atıklarının fabrika sahasını işgal maliyeti ve çevreye zarar vermeyecek şekilde muhafazası için harcanan emek maliyeti dikkate alınmamıştır. Daha ileriki çalışmalarda bu maliyetler de dikkate alınabilir.

\section{Kaynakça}

[1] CCetin, T., 2003. Türkiye Mermer Potansiyeli, Üretimi ve İhracatı, GÜ, Gazi Eğitim Fakültesi Dergisi, Cilt 23, Sayı 3, 243-256.

[2] Kavas T., ve Kibıcı Y., 2001. Afyon Bölgesi Mermer Atıklarının Porlant Kompoze Çimentosu Üretiminde Katkı Maddesi Olarak Kullanım Olanakları, Türkiye 3. Mermer Sempozyumu, MERSEM 2001, 3-5 Mayıs 2001, Afyon.

[3] Kadıŏglu, Y., Özav, L., 2008. Denizli İlinde Önemli Bir Ekonomik Fonksiyon Özelliği Kazanan Endüstriyel Doğal Taşlar : Mermer ve Traverten, Marmara Coğrafya Dergisi, Sayı:8, 253-271.

[4] Kamacı C., 2013. Traverten işlenmesi sırasında karşılaşılan problemler, Eskişehir Osmangazi Üniversitesi, Fen Bilimleri Enstitüsü, Yüksek Lisans Tezi, 97 s., Eskişehir.

[5] Çelik, M.Y., Emrullahoğlu, Ö.F., 1999. Mermer Atıklarından Polyester Bağlayıcılı Suni Mermer Blok ve Levha Üretiminin Araştırılması, Afyon Kocatepe Üniversitesi, Fen Bilimleri Dergisi, $1(1), 35-50$.

[6] Yıldız A.H., 2008. Mermer toz atıklarının yol inşaatında değerlendirilmesi, Süleyman Demirel Üniversitesi, Fen Bilimleri Enstitüsü, Doktora Tezi, 172 s., Isparta.

[7] Bhatnagar, A., 2009. Study for Qualitative and Quantitative Evaluation of Waste Generation in Indian Marble Mining and Processing, Symposium on the Evaluation of Marble Wastes and Decreasing Environmental Effects, 1617 October 2009, Diyarbakır, Turkey, 1-13.
[8] Ceylan, H., Mança, S., 2013. Mermer Parça Atıklarının Beton Agregası Olarak Değerlendirilmesi, Süleyman Demirel Üniversitesi, Teknik Bilimler Dergisi, Cilt 3, Sayı 2, 21-25.

[9] Kun, N. (2013) Mermer Jeolojisi ve Teknolojisi, Genişletilmiş 2. Baskı, Tezer Matbaası, İzmir, $222 \mathrm{~s}$.

[10] Gurer, C., Akbulut, H., Kurklu, G., 2004. İnşaat Endüstrisinde Geri Dönüşüm ve Bir Hammadde Kaynağı Olarak Farklı Yapı Malzemelerinin Yeniden Değerlendirilmesi, 5. Endüstriyel Hammaddeler Sempozyumu Bildiriler Kitabı, 13-14 Mayıs 2004, İzmir, Türkiye, 28-36.

[11] Altındağ, R., 2018. Doğal Taş Ocaklarında Artık Oluşumunun Önlenmesi ve Artıkların Değerlendirilmesi, Mermer Madenciliğinde Çevresel Yaklaşımlar, Muğla Büyükşsehir Belediyesi Kültür Yayınları 6, Akademik Yayın Dizisi:1, Muğla, $271 \mathrm{~s}$.

[12] Filiz, M., Özel, C., Soykan, O., Ekiz, Y., 2010. Atık Mermer Tozunun Parke Taşlarında Kullanılması, Yapı Teknolojileri Elektronik Dergisi, Cilt: 6, No: 2, 57-72.

[13] Akbulut, H., Gurer, C., 2003. Mermer Atıklarının Çevresel Etkileri ve Yol Katmanlarında Kullanılarak Faydalanma ve Atık Azaltma İmkanları, Türkiye IV. Mermer Sempozyumu Bildiriler Kitabı, 18-19 Aralık 2003, Afyonkarahisar, Türkiye, 371-378.

[14] Akbulut, H., Gurer, C. 2006. Atık Mermerlerin Asfalt Kaplamalarda Agrega Olarak Değerlendirilmesi, İMO Teknik Dergi, 17(4), 3943-3960.

[15] Ural, N., Yakşe, G., 2015. Atık Mermer Parçalarının Yol Temel Malzemesi Olarak Değerlendirilmesi, Bilecik Şeyh Edebali Üniversitesi, Fen Bilimleri Dergisi, Cilt:2, Sayı:2, 53-62 s.

[16] Özdemir, E., Sarıcı, D. E., Sarıcı T., 2017. Doğu Anadolu Bölgesinde Bulunan Bazı Mermer Atıklarının Yol Temel ve Alt Temel Tabakalarında Kullanılabilirliğinin Değerlendirilmesi, Dumlupınar Üniversitesi Fen Bilimleri Enstitüsü Dergisi, Sayı 39, 13-20.

[17] Terzi, S., Karaşahin, M., 2003. Mermer Toz Atıklarının Asfalt Betonu Karışımında Filler Malzemesi Olarak Kullanımı, İMO Teknik Dergi, 14(2), 2903-2922.

[18] Okagbue, C.O., Onyeobi, T.U.S., 1999, Potential of Marble Dust to Stabilize Red Tropical Soils for Road Construction, Engineering Geology, Elsevier Science, 53(1999), pp 371-380.

[19] BTSO, 2019. Bucak Sanayi ve Ticaret Odası, 
Bucak Ekonomi, http://www.bucaktso.org.tr /BUCAK/Ekonomi/tabid/16218/Defaultaspx (Erişim Tarihi: 23.07.2019).

[20] Anonim 2013, Karayolu Teknik Şartnamesi, Karayolları Genel Müdürlüğü Yayınları, Ankara.

[21] Sütas, İ., Yılmaz, A., 2006. Elektrik Ark Fırını Cürufunun Karayolu Üstyapısında ve Yol Dolgularında Kullanılabilirliğinin Araștırılması ve Verimlilik Analizi, 003.01.0102.001 No'lu Araştırma Projesi Sonuç Raporu, Akdeniz Üniversitesi, Antalya, $121 \mathrm{~s}$.

[22] Anonim 2018a. Çevre ve Şehircilik Bakanlığı,
Birim Fiyat Tarifleri Eki İnşaat Birim Fiyatları Listesi ve Rayiçleri, 678 s. Ankara.

[23] Anonim 2018b. Yol ve Köprü İnșaatı Fiyat Analizleri, Karayolları Genel Müdürlüğü, 63 s. Ankara.

[24] Ilıcalı, M., 1988. Karayolu üst yapısında Erdemir cürufunun kullanılabilirliğinin araştırılması, Yıldız Teknik Üniversitesi, Fen Bilimleri Enstitüsü, Doktora Tezi, 212 s., İstanbul.

[25] Anonim 2018c. Taşıma Genel Teknik Şartnamesi, Karayolları Genel Müdürlüğü, 525 s. Ankara. 


\section{Ekler}

Ek A. Atık mermerlerin mühendislik özellikleri (Karayolu Teknik Şartnamesi ile karşılaştırmalı)

\begin{tabular}{|c|c|c|c|c|c|c|c|c|c|c|c|c|c|}
\hline Araşt & Irmacı $\rightarrow$ & & $\begin{array}{r}\text { Özder } \\
(20\end{array}$ & $\begin{array}{l}\text { ir v.d. } \\
\text { 7) }\end{array}$ & Ural v & Yakșe & 2015) & (Yıldız & 2008) & $\begin{array}{l}\text { (Akb } \\
\text { Gürer }\end{array}$ & $\begin{array}{l}\text { ut ve } \\
006)\end{array}$ & $\begin{array}{l}\text { Karayol } \\
\text { Şartnan }\end{array}$ & $\begin{array}{l}\text { Teknik } \\
\text { esi [20] }\end{array}$ \\
\hline Atık Mer & mer Cinsi & & $\bar{\varpi}$ & ప రั & $\begin{array}{l}\text { N } \\
\frac{y}{\dot{T}}\end{array}$ & $\bar{\sigma}$ & సี & ब & 종 & $\stackrel{\mathscr{\pi}}{\Xi}$ & क. & Temel & Alttemel \\
\hline Özellik & $\begin{array}{c}\text { Deney } \\
\text { Yöntemi }\end{array}$ & Birim & $\frac{\pi}{\pi}$ & 氞苛 & $\frac{\overrightarrow{0}}{\ddot{0}}$ & $\overline{0}$ & $\stackrel{\Xi}{\beth}$ & 泀 & 龸 & $\sum_{0}^{2}$ & 茜 & $\begin{array}{l}\text { şartname } \\
\text { limiti }\end{array}$ & $\begin{array}{l}\text { Şartname } \\
\text { limiti }\end{array}$ \\
\hline $\begin{array}{l}\text { L.A*. Aşınma } \\
\text { Miktarı/500 } \\
\text { Dev. }\end{array}$ & $\begin{array}{l}\text { TS-EN } \\
1097 / 2\end{array}$ & $\%$ & 20,3 & 28,1 & 14,17 & 11,51 & 13,48 & 22 & 35 & 27,44 & 25,6 & 35 & 45 \\
\hline $\begin{array}{l}\mathrm{MgSO}_{4} \text { Donma } \\
\text { Çözülme } \\
\text { Kaybı }\end{array}$ & $\begin{array}{l}\text { TS-EN } \\
1367 / 2\end{array}$ & $\%$ & 14 & 15,7 & 16,54 & 13,46 & 11,83 & 14,1 & 12,2 & 2,85 & 2,75 & 20 & 25 \\
\hline $\begin{array}{l}\text { Yassilık } \\
\text { İndeksi } \\
\end{array}$ & $\begin{array}{l}\text { TS-EN } \\
933 / 3 \\
\end{array}$ & $\%$ & - & - & 20,87 & 14,52 & 11,94 & - & - & 9,41 & 3,54 & 25 & 30 \\
\hline CBR Değeri & TS $1900-2$ & $\%$ & 122,1 & 120,4 & - & - & - & 121,09 & 122,3 & - & - & 100 & 50 \\
\hline $\begin{array}{l}\text { Su Emme } \\
\text { Yüzdesi }\end{array}$ & $\begin{array}{l}\text { TS-EN } \\
1097 / 6 \\
\end{array}$ & $\%$ & 0,15 & 0,42 & 0,021 & 0,017 & 0,018 & 0,015 & 0,012 & & & 3 & 3,5 \\
\hline $\begin{array}{l}\text { Hacim Özgül } \\
\text { Ağırlık }\end{array}$ & $\begin{array}{l}\text { TS-EN } \\
1097 / 6\end{array}$ & - & - & - & - & - & - & 2,60 & 2,60 & 2,69 & 2,67 & - & - \\
\hline $\begin{array}{l}\text { Maksimum } \\
\text { Kuru } \\
\text { Yoğunluk } \\
\end{array}$ & TS $1900-1$ & $\mathrm{~g} / \mathrm{cm}^{3}$ & 2,47 & 2,41 & - & - & - & 1,91 & 1,91 & - & - & - & - \\
\hline $\begin{array}{l}\text { Optimum Su } \\
\text { Muhtevası }\end{array}$ & TS $1900-1$ & $\%$ & 6,51 & 6,86 & - & - & - & 6,6 & 6,92 & - & - & - & - \\
\hline Likit limit & TS $1900-1$ & $\%$ & NP* & NP & NP & NP & NP & NP & NP & - & - & NP & 25 \\
\hline $\begin{array}{l}\text { Plastisite } \\
\text { indisi }\end{array}$ & TS $1900-1$ & $\%$ & NP & NP & NP & NP & NP & NP & NP & - & - & NP & 6 \\
\hline
\end{tabular}

* NP: Non-plastic

* L.A: Los Angeles Deneyi 